\title{
Analysis of the Harmonizing Potential of Order Processing Attributes in Spread Production Systems
}

\author{
Dirk Oedekoven, Volker Stich, Tobias Brosze, and Stefan Cuber \\ Forschungsinstitut für Rationalisierung e.V. (FIR) an der RWTH Aachen, \\ Pontdriesch 14/16, 52062 Aachen, Germany \\ \{Dirk. Oedekoven, Volker.Stich, Tobias.Brosze\} @fir.rwth-aachen.de
}

\begin{abstract}
The paper discusses an approach how to measure the competitive advantage of harmonized order processing data by making use of knowledge about the interdependencies between related benefit dimensions. Corresponding harmonization projects are all projects that strive for common structures in product attributes, classification systems or product structures. The main objective of the underlying research work is the development of a method for the estimation of the benefit potential of harmonized order processing data.
\end{abstract}

Keywords: classification systems, attribute and data harmonization, analysis of potential, order processing.

\section{Introduction}

\subsection{Initial Situation}

Focusing on core competences, striving for global presence and of course outsourcing sub processes lead to major changes in the set-up of production systems as they became more and more spread all over the world. The increasing number of multi-site enterprises as well as the necessity of integrated coordination throughout supply chains imposes a tremendous challenge to the performance especially of enterprise resource planning (ERP) systems. The support of order processing tasks by IT infrastructure has gained increasing importance since the 80ies [1, 2]. Cross-company processes within the order management are steadily gaining importance. Furthermore a rising number of companies are focussing on efficient communications with their network partners as these actions are more and more understood as strategic instruments of great importance influencing the value of the company $[3,4,5,6]$.

But while efficient order processing turns out to be increasingly important the forces of globalization lead to spread production structures and concurrently to inhomogeneous landscapes of data, attributes and IT-systems. In consequence they face inefficient information flows and processes. The economic and logistic potential within the interfaces of the companies is enormous, independent if it is rooted in intra company networks or between autonomous companies [7, 8, 9]. But although enterprises are eager to harmonize data, attributes and attribute structures they can not evaluate expectable expenses and benefits in advance. This is a major problem for 
initiating projects. In the end projects run out of budget or are not even launched although there is a high potential for improving processes and gaining competitiveness.

The underlying research work of this paper investigates how to estimate the competitive advantage of harmonization projects by making use of knowledge about the interdependencies between benefit dimensions.

\subsection{Problem Definition and Motivation}

Within operational order processing actions system discontinuities inhibit efficiency. This fact can be differentiated by two different causes: On the one hand supply relations between the entities of a production network exist but the use of different ERP systems cause physical incompatibility of the interfaces. This case can be described as the integration gap. On the other hand compatible ERP systems are used, but semantic differences in the order processing data lead to incompatibilities what can be summarized as the standardization gap. Identical products are not automatically a guarantee for synchronized process- and attributes structures. Not standardized processes lead to inadequate ERP system support, even if the objectives are consistent.

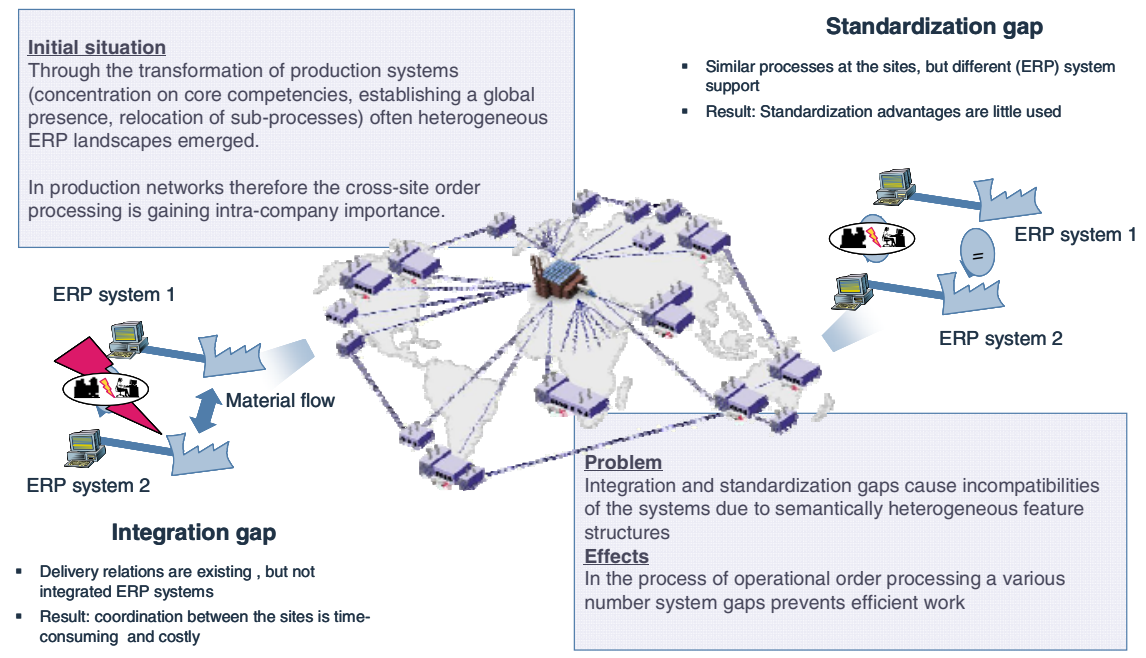

Fig. 1. Initial situation

The results are inefficient information flow and poor transparency. The coordination between the different facilities is time-consuming and costly because integration and standardization potentials are not utilized. In addition operational and cross-site planning to integrate modern concepts for cooperation remains limited. In the end, the extent of the corresponding influences on the company's key figures (e.g. ROCE) cannot be determined currently.

Because of that, harmonization activities are needed, that create an integrated, accurate and consistent data basis for all company-relevant master data, which is already connected to the existing application landscape through corresponding interfaces or a service-oriented architecture [10]. 
The closure of integration- and standardization gaps through corresponding harmonization projects is generally promising a significant improvement of logistical performance on the company- and network level. These improvements could not be quantified yet. An investment to a harmonization plan as an IT project remains undone, if only one of the involved entities appreciates the not negliable investment as too expensive, project risks as too high and the profitability ex ante not to be identified [11]. In times of intense global competition it is these days of particular importance, to ensure the plausibility of costly large-scale projects in terms of their real potential benefits. Otherwise companies are risking their existential business actions through wasting liquid funds.

\subsection{Objective of Research Work}

The objective of this research work is the development of a method for the identification and estimation of the benefit potential of harmonized order processing attributes and data in companies which act within the frame of distributed production structures. The method should be useable to support decision processes regarding investments into harmonization projects.

Because of many partners and parameters the method has to, beside the identification of the complex structure of benefits, include an analysis of interdependency between the single dimensions of benefits. The analysis is necessary to explore the different effects, whether in reinforcing or in inhibiting affection, which occurs because of the correlation of the single dimensions of benefit. Finally the qualitative benefits of potential can be quantified to a certain degree by the usage of such functional chains.

The method should provide an assistance to enable and raise the rationality of the decision for a harmonization project within a company, a group or a network. That is mandatory to thereby provide the basis of modern methods of cost-benefit analysis to make a dedicated profitability analysis for harmonization projects. It is explicitly important to consider the induced dynamics, variety and complexity. This will be guaranteed by locating the respective processes in a reference model that fits the requirements. Lastly the procedure should give assistance to estimate monetary benefits despite some uncertainties.

\subsection{System Theory, Management Cybernetics and the Viable System Model (VSM)}

Existing assessment approaches usually focus on the implementation of specific systems such as SCM or ERP applications only. Indeed, harmonization projects should not only be qualified by verifying their contribution to a systems implementation. Furthermore it is essential to become aware of the total impact of harmonization activities on all strategic goals.

All possible interfaces in the order processing procedure have to be identified in a first step. To narrow the scope of investigation contract manufacturers of products with variants are the initial point of work. Furthermore it is necessary to stick to processes that are suited as references of real actions. An analysis of the reference processes ensures a complete enumeration of all interfaces that may suffer from heterogeneous data and attribute landscapes in and between enterprises. Accordingly for 
each interface a number of potentials can be identified and structured in terms of a set-up benefit model. By developing a coherent target system connecting subordinate objectives of data harmonization with superior objectives such as cycle time reduction, the interdependencies can be evaluated.

The conventional methods of the model theory do not provide fitting approaches to face the system-immanent complexity of production systems. Systems theory and cybernetics specifically start at this point. In contrast to the general approach of engineering or business sciences, these approaches do not exclude the complexity through restrictions and simplifying assumptions, but are setting the focus on it. The discipline of management cybernetics founded by Beer [12] delivers receipts and methods to manage the company effectively because of a system oriented approach.

According to the ideas of management cybernetics the viable systems model (VSM) provides a framework that allows designing reference processes that can cope with real world requirements such as dynamic control loops and mutability. VSM was developed by Beer as a tool for managers to cope with complex systems. Beside Ashbys law, the viable design of a company is in the focus. Viability in Beer's opinion does not mean a ,survival at the subsistence level”, but the continuous preservation of the system identity during environmental changes [13]. The generalized question in the focus is, if a specific configuration of the system can be maintained for a certain time period. In addition, the principle of recursiveness as one of the most important principles for structuring says, that irrespective from the level in which the system is actually located, every system shows a homogenous structure. The basic set-up of a system hierarchy following the principle of recursiveness has the design of systems nested into each other and not the organization theory's well known pyramidic structure [14].

Within the research work a system is considered following Beer as a group of entities, which are dynamically and time-dependent correlated to each other and thereby showing a coherent and connected behaviour.

\section{Research Design}

The following individually described steps are based on the approach to applied research according to Ulrich [15]. The aim is the description and explanation of the impact potential of harmonized order processing data on the company's success. The steps of the research process include terminological-descriptive, empirical-inductive and analytical-deductive components [16].

\subsection{Embedding the Problem within the Viable Systems Model}

The high number of potential interfaces in the order processing procedures are difficult to neglect, and for a scientific analysis not readily to handle. That is why in literature various models occur trying to structure the order processing activities and to provide a uniform description of information interfaces. Nevertheless existing models allow no adequate classification and differentiation of the different starting points for harmonization projects due to their focus and / or their level of detail. In order to 
succeed in an approach to identify potential benefits, the viable systems modelling (VSM) is used and further developed considering the needs of the research work. The development is focusing especially the consideration of dynamic effects in terms of management cybernetics. Accordingly, it serves as a fundamental part of the description model. Basis for the model are given by the spadework of the FIR.

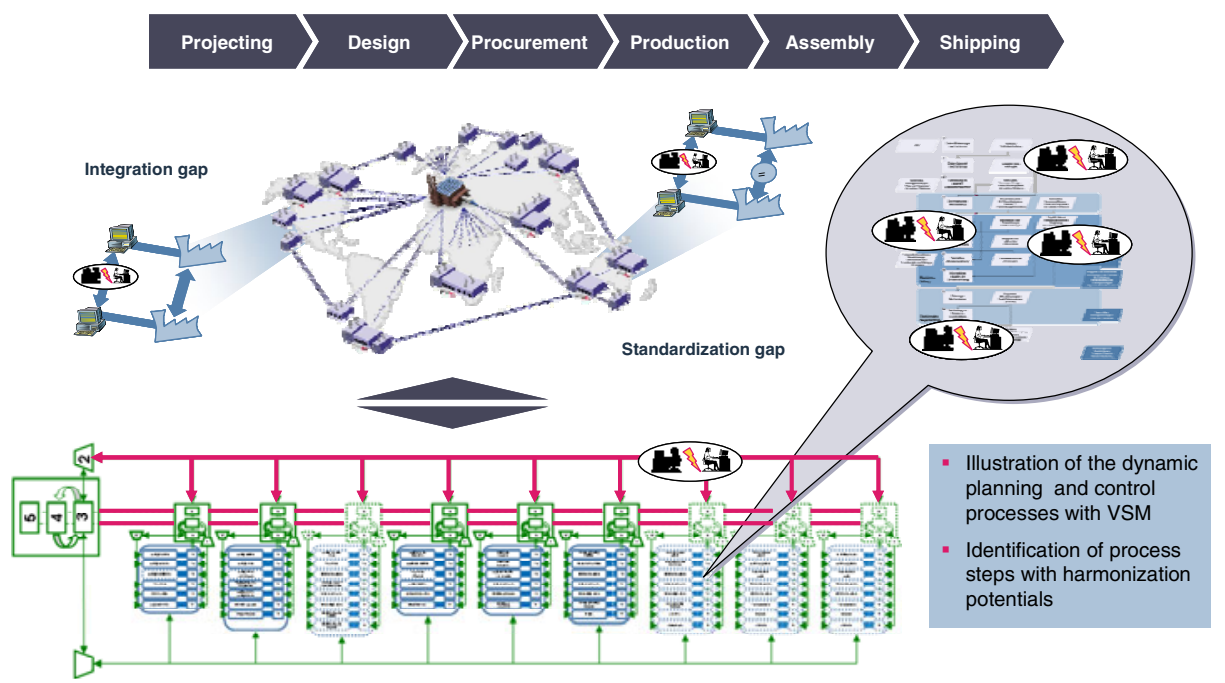

Fig. 2. Embedding the problem within the Viable Systems Model

\subsection{Analysis of the Potential Benefits}

To assess harmonizing potentials in terms of objective economic activity, the implementation of the implied benefit analysis is essential. The objective of economic activity is the maximization of the ratio of a target performance (benefit) for deployment of funds (expenses) [44]. Although therefore the fundamental aspects of economic analysis are relatively simple (design and comparison of expected costs and benefits), a practical implementation is not readily available. So the task is to deal with the six basic problem areas in the benefit analysis of harmonization [45, 46]:

- The problem of holism

- The problem of measurement

- The problem of situation

- The problem of allocation

- The problem of interconnection

- The problem of innovation

As a quintessence of the described problems, it should be noted that the designated benefit provided has to be seen as a potential benefit as far as the uncertainty about its characteristics and probability of occurrence exists. 


\subsection{Development of the Target System and the Utility Model}

The target system that has to be developed is used as a basis for the identification and mapping of benefits of the harmonization project. Among the general business objectives as well as the resulting target and ratio systems numerous approaches in the literature exist from which the relevant work for this system is primarily synthesized [49]. The weighting and possibly the omission of individual goals allows within the application of the description model the individual adjustment of goals.

\subsection{Functional Chain-Based Analysis of the Influence of the Potential Benefits to the Target Elements}

The aim of creating the functional chains is to identify the most important, in a harmonization context occurring interdependencies between potential benefits and target elements in order to assess and to estimate them adequately. The functional effect chains perform as a first step on the path to monetary estimation of the potential benefits. Therefore, they have to be covered as completely as possible [36]. According to the nature of reference models selected connections can be further specified due to cases of application. The top level chains of benefit potential are defined by the relations of the target system. In this respect, the chains of benefit potentials have to be extended with potential benefits which influence the target elements significantly.

\subsection{Design of a Procedure for Identification and Assessment of Potential Benefits in Harmonization Projects}

The final method has to meet different requirements. To meet users expectations and the objectives of the research receivables certain qualities and attributes have to be present. Thereby formal and substantive requirements are to be differentiated, which arise from the problem itself and the objective of the desired method [50]. These requirements should be defined in terms of literature based findings about challenging areas of the benefit analysis. Formal requests describe the general requirements for a method. For example, the utility is an essential formal requirement. Content requirements result analytical-deductively from the objective of the research work; which is in turn empirical-inductively derived from shortcomings in operational practice.

The method that has to be developed for the identification and assessment of potential benefits in harmonization projects finally results out of several activities: the description and positioning of the various potential benefits and costs, the systematic analysis of the interdependencies and by the reference to an integrated target system.

\section{Conclusion}

The challenge for enterprises of being efficient and effective in using their IT infrastructure is gaining more and more importance. Yet a promising approach to evaluate potential benefits in advance is missing. In the field of profitability analysis of order processing in spread production structures the difficulty lies more within the estimation of benefits rather then in the estimation of the efforts. The monetary analysis of 
benefit potentials is so far limited to quantitative dimensions, while the qualitative aspects, which are more difficult to estimate, are often neglected or analyzed only on a general level.

The analysis of the status quo in knowledge has shown that many authors are working on the approaches of the (cybernetic) organizational theory but that there is no attempt to make use of it for evaluating the value proposition of IT. An application of the cybernetic principles to the analysis of system supported processes of order processing activities has not been carried out in the sense of a regulatory framework yet. Nevertheless this seems to be a promising approach as it enables to deal with complexity as well as with dynamics.

Because the mediate potentials of benefit at harmonization projects have a high total ratio, the validation of the effects on a monetary key figure for those systems is highly relevant. The interdependencies between the dimensions of benefit were so far only analyzed isolated and without regarding of cross-sites effects. Therefore the analyzed functional chains do not give a detailed description of the influencing mechanisms, apart from positive/negative influence. But to use functional chains to estimate developments of benefit, the paths of effects can be explored and defined.

By that it can be stated that so far no systematic, scientifically founded derivation of the benefit potentials of harmonized data landscapes of specifying attributes with regard to the perspectives, company, network and the complete supply chain exists. A corresponding possibility to efficiently assess potential benefits and exemplify their interdependencies is missing as well.

The underlying and in this paper described research work addresses these gaps and will provide a solution which meets the relevant requirements. The benefit assessment will be comparable to the cost elements, by providing an adequate economic analysis. Therefore, the focus of this research work lies on the one hand on the identification, categorization and assessment of potential benefits and costs of corresponding harmonization investments and on the other hand on the consideration of the interdependencies between the various benefits. In addition, current methods of economic analysis and to their suitability for the use in specific cases of the harmonization projects are evaluated and adapted.

\section{References}

1. Kernler, H.: PPS der 3. Generation: Grundlagen, Methoden, Anregungen, Hüthig, Heidelberg (1995)

2. Krcmar, H.: Informationsmanagement. Springer, Berlin (1997)

3. Schuh, G., Friedli, T., Kurr, M.A.: Kooperationsmanagement. Hanser, München (2005)

4. Arnold, B.: Strategische Lieferantenintegration. Dissertation Technische Universität Berlin. Deutscher Universitäts-Verlag, Wiesbaden (2004)

5. Lee, H.L.: Creating value through Supply Chain Integration. Supply Chain Management Review 4(4), 30-36 (2000)

6. Ihde, G.: Lieferantenintegration. In: Kern, W., Schröder, H.-H., Weber, J. (eds.) Handwörterbuch der Produktionswirtschaft: Enzyklopädie der Betriebswirtschaftslehre, vol. VIII, pp. 1086-1095. Schäffer-Poeschel Verlag, Stuttgart (1996)

7. Schuh, G.: Referenzstrategien in einer vernetzten Welt. In: Milberg, J., Schuh, G. (eds.) Erfolg in Netzwerken, pp. 17-34. Springer, Berlin (2002) 
8. Schönsleben, P., Luczak, H., Nienhaus, J., Weidemann, M., Schnetzler, M., Roesgen, R.: Supply Chain Management: Monitoring-Lösungen auf dem Vormarsch. IT-Management (5), 10-17 (2003)

9. Busch, A., Lange, H., Langemann, T.: Marktstudie zum Collaborative Supply Chain Management. Heinz Nixdorf Institut, Paderborn (2002)

10. Möbus, D., Richter, G.: Stammdatenstrategie: Nur ein IT Thema?

http://www.cio.de/_misc/article/printoverview/

index. $\mathrm{cfm}$ ?pid=181\&pk=851640\&op=1st

11. Rautenstrauch, T.: SCM-Integration in heterarchischen Unternehmensnetzwerken. In: Busch, A., Dangelmaier, W. (eds.) Integriertes Supply Chain Management, pp. 341-361. Gabler, Wiesbaden (2002)

12. Beer, S.: Kybernetik und Management. Fischer, Frankfurt (1959)

13. Thiem, I.: Ein Strukturmodell des Fertigungsmanagements. Soziotechnische Strukturierung von Fertigungssystemen mit dem Modell lebensfähiger Systeme. Shaker, Aachen (1998)

14. Malik, F.: Strategie des Managements komplexer Systeme: Ein Beitrag zur ManagementKybernetik evolutionärer Systeme, Haupt, Bern (2002)

15. Ulrich, H.: Die Betriebswirtschaftslehre als anwendungsorientierte Sozialwissenschaft. In: Geist, N., Köhler, R. (eds.) Die Führung des Betriebes, Poeschel, Stuttgart, pp. 1-15 (1981)

16. Hill, W., Fehlbaum, R., Ulrich, P.: Organisationslehre 1: Ziele, Instrumente und Bedingungen der Organisation sozialer Systeme. Haupt, Bern (1994)

17. Zangemeister, C.: Erweiterte Wirtschaftlichkeits-Analyse: Grundlagen und Leitfaden für ein 3-Stufen-Verfahren zur Arbeitssystembewertung. Wirtschaftsverlag NW, Bremerhaven (1993)

18. Schumann, M.: Wirtschaftlichkeitsbeurteilung für IV-Systeme. Wirtschaftsinformatik 35(2), 167-178 (1993)

19. Reichwald, R.: Modell einer Wirtschaftlichkeitsrechnung: Einsatz moderner Informationsund Kommunikationstechnik. CIM-Management 3, 6-11 (1987)

20. Lücke, T.: Koordination von intra-organisationalen Produktionsnetzwerken. Shaker, Aachen (2005)

21. Linß, H.: Integrationsabhängige Nutzeffekte der Informationsverarbeitung: Vorgehensmodell und empirische Ergebnisse. Deutscher Universitäts-Verlag, Wiesbaden (1995)

22. Friedrich, M.: Beurteilung automatisierter Prozesskoordination in der technischen Auftragsabwicklung. Shaker, Aachen (2002) 